\title{
Sugammadex: clinical development and practical use
}

\author{
Thomas Fuchs-Buder, Claude Meistelman, and Julien Raft \\ Department of Anesthesiology, Centre Hospitalier Universitaire de NANCY, Hopital de Brabois, Vandoeuvre, France
}

Sugammadex is belonging to a new class of drugs: the selective relaxant binding agents. Sugammadex can reverse residual paralysis by encapsulating free circulating non depolarizing muscle relaxants. The mains advantages of sugammadex when compared with conventional anticholinesterase agents are a much faster recovery time and the unique ability, for the first time, to reverse rapidly and efficiently deep levels of neuromuscular blockade. However it only works for reversal of rocuronium or vecuronium-induced neuromuscular blockade. When administered $3 \mathrm{~min}$ after rocuronium the use of a large dose $(16 \mathrm{mg} / \mathrm{kg})$ can even reverse rocuronium significantly faster than the spontaneous recovery after succinylcholine. (Korean J Anesthesiol 2013; 65: 495-500)

Key Words: Cyclodextrins, Neostigmine, Neuromuscular block, Residual neuromuscular blockade, Rocuronium, Sugammadex.

\section{Introduction}

Residual effects of neuromuscular block are now well identified. They can induce unpleasant effects such as muscle weakness but they can also have have significant clinical consequences and can cause critical respiratory events (CRE) [1,2]. Even 2 hours after a single bolus dose of any intermediate duration of action non depolarizing muscle relaxant (NDMR), one third of the patients have a train of four (TOF) less than 0.9 [3]. Until recently, the action of NDMR could only be reversed by anticholinesterase drugs which temporarily inactivate acetylcholinesterase and increase the amounts of acetylcholine at the postsynaptic membrane. However their use has several pitfalls due to their muscarinic effects, their relatively slow onset or the inability to reverse deep levels of neuromuscular block [4]. The release of Sugammadex since 2009 in Europe after its approval in July 2008 provides a new approach in the management of neuromuscular blockade during surgery and the prevention of residual paralysis at the end of the case.

\section{Pharmacological Properties of Sugammadex}

Cyclodextrins comprise a family of cyclic oligosaccharides, which have been already used in anesthesia to formulate different agents used in anesthesia including propofol, etomidate, bupivacaine, sufentanil or intranasal midazolam. Sugammadex is a modified $\gamma$-cyclodextrin specifically designed to encapsulate rocuronium and chemically similar aminosteroidal muscle relaxants such as vecuronium [5]. The underlying mechanism of action is new and differs completely from that of acetylcholine esterase inhibitors. When sugammadex is introduced in blood, the free molecules of rocuronium in plasma which are in equi-

Received: August 27, 2013. Accepted: September 6, 2013.

Corresponding author: Thomas Fuchs-Buder, M.D., Department of Anesthesiology, Centre Hospitalier Universitaire de NANCY, Hopital de Brabois, rue du Morvan, 54500 Vandoeuvre, France. Tel: 33-383-15-39-42, Fax: 33-383-15-43-42, E-mail: t.fuchs-buder@chu-nancy.fr (c) This is an open-access article distributed under the terms of the Creative Commons Attribution Non-Commercial License (http:// creativecommons.org/licenses/by-nc/3.0/), which permits unrestricted non-commercial use, distribution, and reproduction in any medium, provided the original work is properly cited. 
librium with the tissues are almost immediately captured by the sugammadex molecules and the plasma free rocuronium concentration decreases very rapidly [6]. This creates a gradient of rocuronium between tissue and plasma, with rocuronium molecules moving out of the tissue and into plasma where they are encapsulated by free sugammadex molecules. The diffusion of sugammadex onto the tissues and formation of complexes at the neuromuscular junction remains discussed. Following administration of sugammadex, the concentration of free rocuronium decreases rapidly in the plasma but the total rocuronium plasma concentration (free and bound to sugammadex) increase rapidly [7]. Then, the complex will be rapidly filtered by the glomerulus and eliminated through the kidney. Sugammadex has no direct effect on cholinergic transmission. It is considered as a selective relaxant binding drug (SRBA). Sugammadex does not exhibit intrinsic biological activity.

Sugammadex selectively reverses steroidal neuromuscular blockade (NMBA), particularly rocuronium but also vecuronium. Its selectivity for steroidal NMBA over atracurium or succinylcholine is due to the size of its inner cavity and its structural complementarity with the right hydrophobic steroidal skeleton. It does not have any affinity for more than 40 drugs that may be used during anesthesia (hypnotics, analgesics, antibiotics, cardiovascular drugs). Affinity for cortisone, hydrocortisone, aldosterone has been extensively studied because sugammadex binds strongly to steroidal NMBA, affinity is 120 fold less than for rocuronium. Affinity for atropine, verapamil, ketamine is 400 to 700 fold lower than for rocuronium. Among many molecules studied, toremifene and flucloxacillin are the only molecules known to displace rocuronium or vecuronium from sugammadex.

Initial studies in adult patients have confirmed that sugammadex, administered at reappearance of $\mathrm{T} 2$ of the TOF reversed $0.6 \mathrm{mg} / \mathrm{kg}$ rocuronium-induced neuromuscular block in a dosedependant manner. At doses of sugammadex at or above $2.0 \mathrm{mg} /$ $\mathrm{kg}$ recovery occurred within $3 \mathrm{~min}$ without any sign of recurarisation [8-10]. When compared with neostigmine for reversal of neuromuscular block at reappearance of 4 TOF responses it have been shown that a 0.90 TOF ratio was obtained in approximately 2 min with sugammadex compared to a time of 17 min using néostigmine [11]. Moreover, 2-4 mg/kg sugammadex when given at reappearance of $\mathrm{T} 2$ in prolonged rocuronium-induced block ( $>2 \mathrm{~h}$ ) effectively reversed rocuronium [12]. It was also shown that there are no differences in time taken to reach a 0.9 TOF ratio after anesthesia maintained with halogenated agents when compared with propofol [13]. Although sugammadex was developed to antagonize rocuronium-induced block; it is also effective in reversing $0.1 \mathrm{mg} / \mathrm{kg}$ vecuronium-induced block [14]. When given at reappearance of $\mathrm{T} 2$, recovery of a 0.9 TOF ratio was obtained in $2.3 \mathrm{~min}$ and $1.5 \mathrm{~min}$ following 2.0 and $4.0 \mathrm{mg} /$ kg respectively [15].

During deep level of block (less than 2 responses at the TOF, neither rocuronium nor vecuronium can be reversed satisfactorily within a short period of time using neostigmine. Profound neuromuscular block (Post-tetanic count: 1 or 2) can be rapidly and safely reversed with sugammadex in humans. With 4 or 8 $\mathrm{mg} / \mathrm{kg}$, a 0.9 TOF ratio could be obtained in $3.3 \mathrm{~min}$ (range 2.2$4.7 \mathrm{~min}$ ) and $1.5 \mathrm{~min}$ (1.0-2.1 $\mathrm{min}$ ) respectively [10].

There are situations in which deep block must be reversed very rapidly, for example when tracheal intubation has failed. When given, $3 \mathrm{~min}$ after $1.2 \mathrm{mg} / \mathrm{kg}$ rocuronium, $16 \mathrm{mg} / \mathrm{kg} \mathrm{su}$ gammadex can completely reverse the block in less than $3 \mathrm{~min}$ [16]. In this setting, recovery with sugammadex is significantly faster than spontaneous recovery from succinylcholine.

\section{Sugammadex Versus Neostigmine Is It Worth It?}

In 1954, Beecher and Todd [17] suggested that the use of NMBA could significantly increase the mortality rate during general anesthesia. These findings were due to the non routine use of controlled ventilation in these patients but also to residual paralysis and likely CRE after surgery. Therefore, in the early $60 \mathrm{~s}$ Cecil Gray suggested the routine administration of $5 \mathrm{mg}$ neostigmine at the end of surgery to prevent residual paralysis, when long acting NMBA were used. For over 40 years anticholinesterases have been widely used to reverse neuromuscular block at the end of the case, the most commonly employed being neostigmine.

Many studies have confirmed the efficiency of anticholinesterase agents. Baillard et al. [18] have clearly demonstrated that the rate of residual paralysis in the recovery room had very significantly decreased over 10 years by routine use on monitoring of neuromuscular block in association with administration of neostigmine when residual paralysis was detected. The rate of residual blockade as defined as a TOF ratio $<0.9$ decreased from 62 to $3 \%$, confirming the benefit of reversal in routine anesthetic practice. In the same time, Arbous et al. [19] by studying the morbidity and mortality rate in more than 850,000 patients in Holland was able to demonstrate that the use of reversal agents at the end of the case could induce a very significant decrease in morbidity and mortality (odd ratio: 0.10 ; $95 \%$ confidence interval: 0.032-0.314).

Therefore the need for a new reversal agent with a completely different mode of action such as sugammadex should to be evaluated versus the routine use of conventional anticholinesterase agents.

Neostigmine but also edrophonium show several pitfalls. There is the absolute need to use them in association with atropine or glycopyrrolate to avoid side effects such as tachycardia 
and hypotension. The concomitant use of atropine induces its own side effects such as tachycardia, dry mouth and blurred vision. Therefore neostigmine may be contraindicated in patients with cardiovascular disease or severe asthma. A less evident limitation of neostigmine is its relatively slow onset of action. Increasing doses to shorten its onset is not a valuable option because neostigmine exhibits a ceiling effect for doses greater than $70 \mu \mathrm{g} / \mathrm{kg}$ because of the limited amount of acetylcholine at the neuromuscular junction. Moreover, recovery of shallow levels of neuromuscular block (at least 2 responses at the TOF at the adductor pollicis) following neostigmine is not as fast as usually thought. Kopman had demonstrated that when neostigmine was given during shallow rocuronium or cisatracuriuminduced neuromuscular block at 2 responses at the TOF, the TOF ratio attained 0.76 and 0.72 respectively $10 \mathrm{~min}$ after administration [20]. These findings were confirmed by Blobner et al. [21] who have demonstrated that the median time to reach a 0.9 TOF ratio following neostigmine administered after reappearance of 2 twitches was $18.5 \mathrm{~min}$. One major issue was the large interindividual variability; even $60 \mathrm{~min}$ after neostigmine administration less than $90 \%$ of the patients had reached a 0.9 TOF ratio. These findings have clinical consequences because it is now fully admitted that TOF ratios less than 0.9 are associated with adverse respiratory events, including reduced upper airway volumes, airway obstruction, hypoxemia events, and postoperative pulmonary complications [1]. The upper airway muscles are particularly sensitive to the effects of NDMR [22]. For example, upper esophageal tone is decreased and the incidence of aspiration is increased for TOF ratios less than 0.9 [23]. After giving neostigmine, there is a risk for the anesthetist to feel overconfident and to extubate the patient whereas a 0.9 TOF ratio has not been yet reached.

In the elderly patients, the time needed to a $0.9 \mathrm{TOF}$ ratio does not differ very much (2.9 min) when compared with younger patients. As for any NMBA, this very mild slower onset of action in the elderly could be due to circulatory factors such as altered muscle perfusion or decreased cardiac output [24]. There are few data in pediatric patients. Plaud et al. [25] have demonstrated that sugammadex could be used safely at a dose of $2 \mathrm{mg} / \mathrm{kg}$ and that recovery times were similar in children and adolescents when compared with adults. Although there was a small number of infants studied, recovery time to obtain a 0.9 TOF ratio, after sugammadex, was rapid ranging from 0.6 to $3.7 \mathrm{~min}$.

There is another major limitation of neostigmine; it is efficient only after beginning of spontaneous recovery. Therefore, there has always be an unsatisfied need for a reversal agent that can rapidly reverse neuromuscular block regardless of its depth. Jones et al. [26] compared the efficacy of sugammadex versus neostigmine for reversal of deep level of rocuronium-induced paralysis. Sugammadex or neostigmine was given at reappear- ance of 1 to 2 responses at the PTC when no responses at the TOF at the adductor pollicis could be detected. A 0.9 TOF ratio was attained in 2.9 min with sugammadex versus $50.4 \mathrm{~min}$ in patients receiving neostigmine - glycopyrrolate. The most important finding was the reproducibility and the small range when sugammadex is given, $97 \%$ of patients receiving sugammadex had a TOF ratio above 0.9 within 5 min of administration, whereas a large number of patients receiving neostigmine did not recover until 30-60 min and 23\% did not recover to a 0.9 TOF ratio until more than $60 \mathrm{~min}$ (Fig. 1). These results were confirmed by other studies, which have also confirmed the ineffectiveness of neostigmine for the reversal in this setting. Sabo et al. [27] found that after reversal at 1 or more PTC, a 0.9 TOF ratio was reached at or before extubation in $96 \%$ of patients receiving sugammadex versus $39.5 \%$ of patients who received néostigmine.

This ability to reverse very rapidly and reliably intense neuromuscular block provides the opportunity to maintain it until the complete end of the procedure. There are clinical situations where the surgeon needs complete relaxation of the patient until the end of the case (major abdominal or thoracic surgery, laparoscopic surgery) and where the anesthetist is reluctant to provide full paralysis because it will delay significantly recovery and turn over of the patients in the operating room. Now it is possible to maintain paralysis of the diaphragm and the abdominal wall muscles which are resistant to the effects of NMBA [28-30] when compared with peripheral muscles such as the adductor pollicis until the very-end of the procedure. However in this kind of situation, the anesthetist should remember that the requested dose of sugammadex will be 4 and not $2 \mathrm{mg} / \mathrm{kg}$ sugammadex. Therefore, the need for monitoring remains important since it is the only objective manner to follow evolution of deep neuromuscular block and decide of the dose of sugammadex

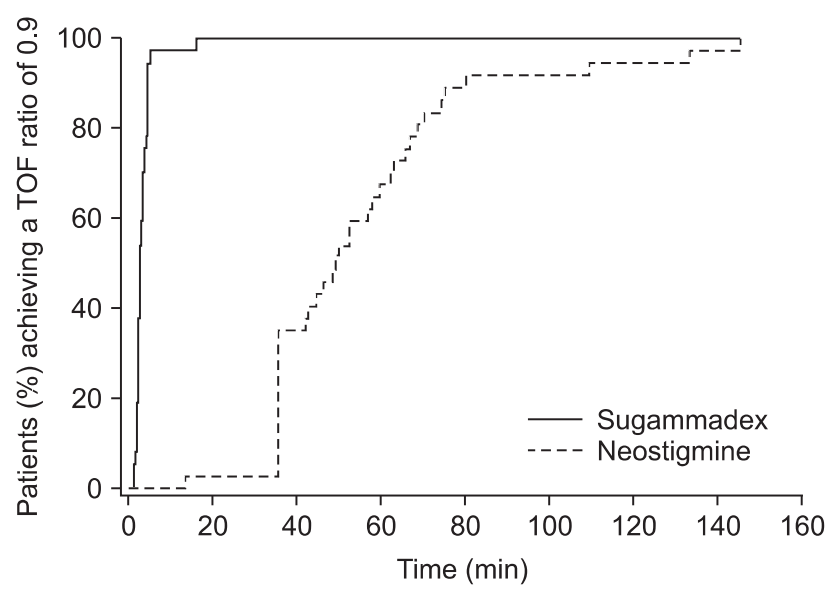

Fig. 1. Time to recovery of a $0.9 \mathrm{TOF}$ ratio from deep rocuronium-induced neuromuscular blockade after administration of sugammadex or neostigmine (adapted from Ref 26). TOF: train of four. 
that need to be administered ( 2 or $4 \mathrm{mg} / \mathrm{kg}$ ) at the end of the case.

To summarize, the main advantages of sugammadex, when compared with neostigmine or edrophonium, are a significantly faster and more predictable recovery and the possibility for the first time to reverse efficiently and very rapidly deep levels of neuromuscular block. Moreover, the use of inhalation anesthetics which usually prolong recovery times have no impact on the efficacy of sugammadex.

\section{Side Effects}

Because sugammadex does not act as neostigmine or edrophonium, by inhibition of acetylcholinesterase and indirect action on receptors, but by encapsulation in the plasma, it is not expected to have such side effects than anticholinesterase agents. Most of the related side effects observed in phase II and III studies were unspecific including hypotension, movement coughing, dry mouth or nausea. Prolongation of the corrected QT interval have been described but with the same rate than in the placebo group. This can be observed with several anesthetic agents; therefore its signification was highly questionable. Dahl et al. [31] have confirmed the lack of cardiovascular effects of both 2 and $4 \mathrm{mg} / \mathrm{kg}$ sugammadex in patients with cardiovascular disease undergoing non cardiac surgery.

The imprint of sugammadex has been recently supplemented with the notification of eventual longer clotting time in the first minutes following its administration without any documented clinical consequences. In an observational study, Raft et al. [32] investigated before, 1 hour after sugammadex administration and on the next day: clinical bleeding, hemoglobin concentration, hematocrit, activated partial thromboplastin time (aPTT) and prothrombin time (PT) in 142 patients scheduled for major abdominal cancer surgery and at risk of surgical bleeding. They did not find any significant differences between the control group (no sugammadex) and the groups receiving either 2 or $4 \mathrm{mg} / \mathrm{kg}$ sugammadex in terms of clinical bleeding. Its administration was not associated with a longer clotting time neither decreased hemoglobin concentration.

Any NMBA can cause anaphylactic reaction because quaternary ammonium ions are suggested to be the allergenic determinants in NMBAs. In most of the case cross reactivity can be observed even between steroidal and benzylisoquinoline NMBA [33]. The use of sugammadex to capture rocuronium and to be an adjunct in the management of rocuronium-induced anaphylactic complication has been suggested. There are a few clinical cases where sustained hemodynamic improvement (increase in blood pressure and normalization of heart rate) was observed during rocuronium anaphylactic event, after administration of sugammadex. Baldo [34] has suggested that sugammadex could eventually interact with mast cells. However there is not yet enough scientific evidence to recommend sugammadex as the treatment of choice during anaphylactic reaction due to steroidal NMBA.

\section{Will Sugammadex Change Our Practice of Anesthesia?}

NMBA are used routinely for many surgical procedures because they provide adequate abdominal muscular relaxation. Some authors have suggested that NMBA do not need to be used routinely for example during retroperitoneal or retropubic surgery. A prospective controlled study has clearly demonstrated that NMBA (vecuronium) decrease very significantly the rate of unacceptable conditions in patients undergoing retropubic surgery even if halogenated agents were used for maintenance of anesthesia. Moreover the surgeons found that abdominal muscle relaxation as estimated by clinical judgement increase with increasing doses of vécuronium [35]. The diaphragm and the abdominal wall muscles are the most resistant muscles of the body to NMBA. In some case the surgeon could complain about the intensity of the block because the diaphragm has already started its recovery or the patient is coughing whereas the peripheral muscles such as the adductor pollicis were still fully paralyzed with no response at the TOF at the adductor pollicis $[29,36]$. Up to know anesthesiologists have been rather reluctant to use these deep levels of neuromuscular block up to the very end of the surgical procedure because until now it was impossible to reverse deep neuromuscular block. This kind of situation should not be a problem anymore because it will be possible to fully paralyze the diaphragm and the abdominal wall muscles with greater doses of steroidal NMBA and to maintain this deep block until the closure or the removal of the last device during laparoscopic surgery.

Now that anesthesiologists have available many drugs with a short offset (desflurane, sevoflurane, propofol, remifentanil) it will also be possible to have a very precise control of neuromuscular block when steroidal NMBA are used to maintain relaxation and to obtain, for the first time, a rapid and reliable recovery from deep neuromuscular block.

\section{Conclusion}

Sugammadex is a very exciting drug because, for the first time, we have a molecule that can reverse easily and rapidly any level of vecuronium or rocuronium-induced neuromuscular block when given at the appropriate dose. Moreover, the reversal time is greatly reproducible from a patient to an other. The use of sugammadex could make anesthesia much easier and safer. It would become possible to reverse the block exactly when 


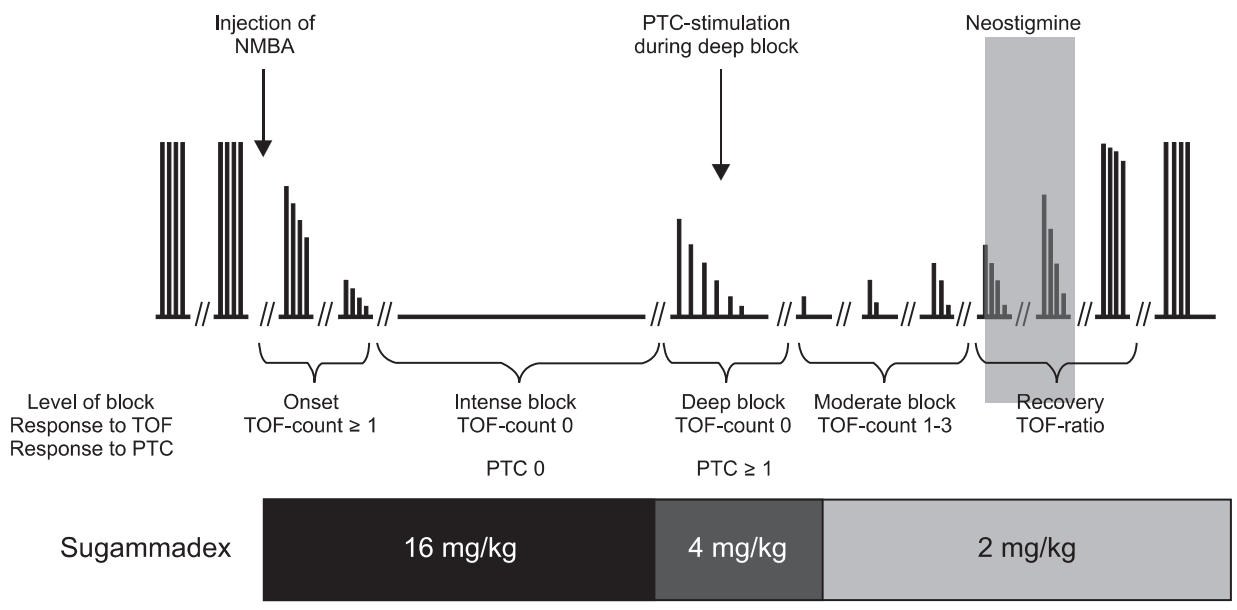

Fig. 2. Recommended doses of sugammadex depending of the degree of neuromuscular blockade. NMBA: neuromuscular blockade, PTC: plasma thromboplastin component, TOF: train of four. needed and no residual paralysis should be observed anymore in the recovery room. Based on the studies, it is recommended to use $2.0 \mathrm{mg} / \mathrm{kg}$ for reversing a shallow rocuronium block. Deep rocuronium-induced block can be easily and rapidly reversed with $4 \mathrm{mg} / \mathrm{kg}$ sugammadex. This dose is not associated with any recurrence of block. A dose of $16 \mathrm{mg} / \mathrm{kg}$ can efficiently and rapidly reverses rocuronium 3 min after its administration
(Fig. 2). It is now obvious that introduction of sugammadex into clinical practice has increased our therapeutic options. Should we withdraw neostigmine from our clinical use? Certainly not, because it is the only reversal agent acting against residual paralysis induced by benzylisoquinoline NDMR. Moreover, it use can still be discussed for the low levels of residual paralysis such as a TOF ratio above 0.4 [37].

\section{References}

1. Murphy GS, Szokol JW, Marymont JH, Greenberg SB, Avram MJ, Vender JS. Residual neuromuscular blockade and critical respiratory events in the postanesthesia care unit. Anesth Analg 2008; 107: 130-7.

2. Murphy GS, Szokol JW, Avram MJ, Greenberg SB, Marymont JH, Vender JS, et al. Intraoperative acceleromyography monitoring reduces symptoms of muscle weakness and improves quality of recovery in the early postoperative period. Anesthesiology 2011; 115: 946-54.

3. Debaene B, Plaud B, Dilly MP, Donati F. Residual paralysis in the PACU after a single intubating dose of nondepolarizing muscle relaxant with an intermediate duration of action. Anesthesiology 2003; 98: 1042-8.

4. Plaud B, Debaene B, Donati F, Marty J. Residual paralysis after emergence from anesthesia. Anesthesiology 2010; 112: 1013-22.

5. Zhang MQ. Drug-specific cyclodextrins: the future of rapid neuromuscular block reversal? Drugs Future 2003; 28: 347-54.

6. Bom A, Bradley M, Cameron K, Clark JK, Van Egmond J, Feilden H, et al. A novel concept of reversing neuromuscular block: chemical encapsulation of rocuronium bromide by a cyclodextrin-based synthetic host. Angew Chem Int Ed Engl 2002; 41: 266-70.

7. Epemolu O, Bom A, Hope F, Mason R. Reversal of neuromuscular blockade and simultaneous increase in plasma rocuronium concentration after the intravenous infusion of the novel reversal agent Org 25969. Anesthesiology 2003; 99: 632-7.

8. Sorgenfrei IF, Norrild K, Larsen PB, Stensballe J, Ostergaard D, Prins ME, et al. Reversal of rocuronium-induced neuromuscular block by the selective relaxant binding agent sugammadex: a dose-finding and safety study. Anesthesiology 2006; 104: 667-74.

9. Gijsenbergh F, Ramael S, Houwing N, van Iersel T. First human exposure of Org 25969, a novel agent to reverse the action of rocuronium bromide. Anesthesiology 2005; 103: 695-703.

10. Groudine SB, Soto R, Lien C, Drover D, Roberts K. A randomized, dose-finding, phase II study of the selective relaxant binding drug, Sugammadex, capable of safely reversing profound rocuronium-induced neuromuscular block. Anesth Analg 2007; 104: 555-62.

11. Sacan O, White PF, Tufanogullari B, Klein K. Sugammadex reversal of rocuronium-induced neuromuscular blockade: a comparison with neostigmine-glycopyrrolate and edrophonium-atropine. Anesth Analg 2007; 104: 569-74.

12. Shields M, Giovannelli M, Mirakhur RK, Moppett I, Adams J, Hermens Y. Org 25969 (sugammadex), a selective relaxant binding agent for antagonism of prolonged rocuronium-induced neuromuscular block. Br J Anaesth 2006; 96: 36-43.

13. Vanacker BF, Vermeyen KM, Struys MM, Rietbergen H, Vandermeersch E, Saldien V, et al. Reversal of rocuronium-induced neuromuscular block with the novel drug sugammadex is equally effective under maintenance anesthesia with propofol or sevoflurane. Anesth Analg 2007; 104: 563-8.

14. Duvaldestin P, Kuizenga K, Saldien V, Claudius C, Servin F, Klein J, et al. A randomized, dose-response study of sugammadex given for the reversal of deep rocuronium- or vecuronium-induced neuromuscular blockade under sevoflurane anesthesia. Anesth Analg 2010; 110: 74-82. 
15. Suy K, Morias K, Cammu G, Hans P, van Duijnhoven WG, Heeringa M, et al. Effective reversal of moderate rocuronium- or vecuroniuminduced neuromuscular block with sugammadex, a selective relaxant binding agent. Anesthesiology 2007; 106: 283-8.

16. Lee C, Jahr JS, Candiotti KA, Warriner B, Zornow MH, Naguib M. Reversal of profound neuromuscular block by sugammadex administered three minutes after rocuronium: a comparison with spontaneous recovery from succinylcholine. Anesthesiology 2009; 110: $1020-5$.

17. Beecher HK, Todd DP. A study of the deaths associated with anesthesia and surgery: based on a study of 599,548 anesthesias in ten institutions 1948-1952, inclusive. Ann Surg 1954; 140: 2-35.

18. Baillard C, Clec'h C, Catineau J, Salhi F, Gehan G, Cupa M, et al. Postoperative residual neuromuscular block: a survey of management. Br J Anaesth 2005; 95: 622-6.

19. Arbous MS, Meursing AE, van Kleef JW, de Lange JJ, Spoormans HH, Touw P, et al. Impact of anesthesia management characteristics on severe morbidity and mortality. Anesthesiology 2005; 102: 257-68.

20. Kopman AF, Zank LM, Ng J, Neuman GG. Antagonism of cisatracurium and rocuronium block at a tactile train-of-four count of 2: should quantitative assessment of neuromuscular function be mandatory? Anesth Analg 2004; 98: 102-6.

21. Blobner M, Eriksson LI, Scholz J, Motsch J, Della Rocca G, Prins ME. Reversal of rocuronium-induced neuromuscular blockade with sugammadex compared with neostigmine during sevoflurane anaesthesia: results of a randomised, controlled trial. Eur J Anaesthesiol 2010; 27: 874-81.

22. Eikermann M, Vogt FM, Herbstreit F, Vahid-Dastgerdi M, Zenge MO, Ochterbeck C, et al. The predisposition to inspiratory upper airway collapse during partial neuromuscular blockade. Am J Respir Crit Care Med 2007; 175: 9-15.

23. Eriksson LI, Sundman E, Olsson R, Nilsson L, Witt H, Ekberg O, et al. Functional assessment of the pharynx at rest and during swallowing in partially paralyzed humans: simultaneous videomanometry and mechanomyography of awake human volunteers. Anesthesiology 1997; 87: 1035-43.

24. McDonagh DL, Benedict PE, Kovac AL, Drover DR, Brister NW, Morte JB, et al. Efficacy, safety, and pharmacokinetics of sugammadex for the reversal of rocuronium-induced neuromuscular blockade in elderly patients. Anesthesiology 2011; 114: 318-29.

25. Plaud B, Meretoja O, Hofmockel R, Raft J, Stoddart PA, van Kuijk JH, et al. Reversal of rocuronium-induced neuromuscular blockade with sugammadex in pediatric and adult surgical patients. Anesthesiology 2009; 110: 284-94.

26. Jones RK, Caldwell JE, Brull SJ, Soto RG. Reversal of profound rocuronium-induced blockade with sugammadex: a randomized comparison with neostigmine. Anesthesiology 2008; 109: 816-24.

27. Sabo D, Jones RK, Berry J, Sloan T, Chen J, Morte JB, et al. Residual neuromuscular blockade at extubation: a randomized comparison of sugammadex and neostigmine reversal of rocuronium-induced blockade in patients undergoing abdominal surgery. J Anesthe Clinic Res 2011 June [2011 June 02]. Avaliable from http://www.omicsonline.org/2155-6148/2155-6148-2-140.pdf

28. Pansard JL, Chauvin M, Lebrault C, Gauneau P, Duvaldestin P. Effect of an intubating dose of succinylcholine and atracurium on the diaphragm and the adductor pollicis in humans. Anesthesiology 1987; 67: 326-30.

29. Donati F, Meistelman C, Plaud B. Vecuronium neuromuscular blockade at the diaphragm, the orbicularis oculi, and adductor pollicis muscles. Anesthesiology 1990; 73: 870-5.

30. Kirov K, Motamed C, Dhonneur G. Differential sensitivity of abdominal muscles and the diaphragm to mivacurium: an electromyographic study. Anesthesiology 2001; 95: 1323-8.

31. Dahl V, Pendeville PE, Hollmann MW, Heier T, Abels EA, Blobner M. Safety and efficacy of sugammadex for the reversal of rocuroniuminduced neuromuscular blockade in cardiac patients undergoing noncardiac surgery. Eur J Anaesthesiol 2009; 26: 874-84.

32. Raft J, Betala Belinga JF, Jurkolow G, Desandes E, Longrois D, Meistelman C. Clinical evaluation of post-surgical bleeding after a sugammadex injection. Ann Fr Anesth Reanim 2011; 30: 714-7

33. Dewachter P, Mouton-Faivre C, Emala CW. Anaphylaxis and anesthesia: controversies and new insights. Anesthesiology 2009; 111: 114150.

34. Baldo B. Sugammadex and rocuronium-induced anaphylaxis. Anaesthesia 2012; 67: 1174-5.

35. King M, Sujirattanawimol N, Danielson DR, Hall BA, Schroeder DR, Warner DO. Requirements for muscle relaxants during radical retropubic prostatectomy. Anesthesiology 2000; 93: 1392-7.

36. Plaud B, Debaene B, Donati F. The corrugator supercilii, not the orbicularis oculi, reflects rocuronium neuromuscular blockade at the laryngeal adductor muscles. Anesthesiology 2001; 95: 96-101.

37. Fuchs-Buder T, Meistelman C, Alla F, Grandjean A, Wuthrich Y, Donati F. Antagonism of low degrees of atracurium-induced neuromuscular blockade: dose-effect relationship for neostigmine. Anesthesiology 2010; 112: 34-40. 